\title{
ACESSIBILIDADE EM CALÇADAS DA UNIVERSIDADE FEDERAL DE PERNAMBUCO
}

\section{ACCESSIBILITY OF SIDEWALKS IN FEDERAL UNIVERSITY OF PERNAMBUCO}

\author{
LIRA, Ana Karina Morais de (1); \\ LIRA, Carlos André Morais de (2) \\ (1) Universidade Federal de Pernambuco, PhD \\ e-mail: karina@ufc.br \\ (2) Companhia Brasileira de Trens Urbanos, Engenheiro Civil \\ e-mail: carlosmlira@gmail.com
}

\begin{abstract}
RESUMO
Neste trabalho discutimos as condições de acessibilidade de calçadas do Campus Recife da Universidade Federal de Pernambuco (UFPE), cuja avaliação foi proposta por alunos com deficiência. A pesquisa de campo incluiu a verificação in loco, com uso de técnicas de análise walkthrough com pessoas com deficiência motora e visual, relato de vivência e levantamento técnico envolvendo check list e registros escrito e fotográfico. Entre outros aspectos, a análise aponta que há ausência de rebaixamento de guias e problemas na sinalização tátil instalada nas novas calçadas, o que indica a necessidade de realizar adequações, atendendo-se as normas técnicas e legislação vigente.
\end{abstract}

Palavras-chave: Acessibilidade física; calçadas; Análise walkthrough; Pessoas com deficiência motora e visual.

\section{ABSTRACT}

This study discusses the conditions of accessibility of sidewalks in Federal University of Pernambuco (UFPE), whose evaluation was proposed by students with disabilities. The field research included a verification in loco, using techniques of walk through with people with physical and visual disabilities, experience report and technical survey involving check list and written and photographic records. Among other things, the analysis indicates that there is absence of dropped curbs/ramps and problems in tactile signage installed in new sidewalks, which indicates the need for adjustments, taking up technical standards and current legislation.

Keywords: Physical accessibility; Sidewalks: Walkthrough analysis; People with physical and visual disabilities

O presente estudo versa sobre condições de acessibilidade em calçadas da Universidade Federal de Pernambuco (UFPE), cuja avaliação foi motivada por solicitação de alunos com deficiência matriculados nos cursos de Pedagogia e Música, os quais tem enfrentado dificuldades para se locomover e circular em áreas do Campus Recife da UFPE e para 
utilizar os serviços do Restaurante Universitário (RU), entre outros.

Abordado através do enfoque da ergonomia do ambiente construído, esse tema-problema é remetido ao ambiente físico da tarefa e a adaptação do mesmo às habilidades e limitações humanas no desenvolvimento de suas atividades (FONSECA; RHEINGANTZ, 2009; VASCONCELOS; VILLAROUCO; SOARES, 2010). Nessa perspectiva, a seguinte questão central é formulada: o ambiente físico representado pelas calçadas da UFPE está adequado para a utilização por pessoas cegas e por usuários de cadeiras de rodas? No âmago dessa questão está a relação que pessoas cegas e usuários de cadeiras de rodas estabelecem com as calçadas na experiência de se locomoverem através das mesmas.

Nesse enfoque ergonômico - que envolve o trinômio ambiente construído, comportamento humano e desempenho de tarefa - dois elementos são considerados fundamentais para o estudo da relação homem-ambiente: as características humanas no desenvolvimento de suas atividades e as tarefas realizadas (VILLAROUCO; ANDRETO, 2008; OLIVEIRA; RANGEL; MONT'ALVÃO, 2013). De forma a responder questões como a que formulamos acima, portanto, a ergonomia ambiental - e por extensão, a arquitetura e a engenharia, que lidam com a concepção de projetos, entre outras atividades - passa a demandar o conhecimento sobre pessoas com deficiência.

Nas últimas décadas, a crescente difusão do movimento mundial de inclusão social tem gerado uma intensa demanda pelo conhecimento sobre pessoas com deficiência nos mais variados domínios e campos do saber. Em nossa experiência de trabalho envolvendo esse público, temos tido oportunidade de atuar em conjunto com profissionais de áreas tão diversas como a saúde, educação, arquitetura e urbanismo, engenharia de sistemas, biblioteconomia, turismo e lazer, havendo acompanhado processos de descoberta, elaboração e aplicação desse conhecimento por vários colegas.

No âmbito das ações das quais participamos, temos adotado três princípios básicos. Em primeiro lugar, pressupomos que a acessibilidade é necessária a todas as atividades realizadas pelo homem, ou seja, que o ambiente em que vivemos - seja físico, digital, social, cultural, psicológico etc. - deve ser organizado de forma tal que sejam eliminadas ou minimizadas todas as barreiras que impedem que pessoas com deficiência realizem toda e qualquer atividade. Esta concepção associa-se a idéia de que, assim como qualquer ser humano, a pessoa com deficiência é um cidadão de direito, desejo, necessidade, vontade $1 . .$. devendo, portanto, ter oportunidade de participar da vida social em todas as suas nuances.

Em segundo, pressupomos que ações em prol das pessoas com deficiência não podem prescindir da participação das mesmas, devendo caracterizar-se como ações com pessoas com deficiência e não para pessoas com deficiência. Isto está em consonância com o lema nada sobre nós sem nós, adotado pelo movimento social das pessoas com deficiência e fundamenta-se em uma concepção da pessoa com deficiência como sujeito ativo, cuja vivência e visão de mundo devem assumir um papel primordial para a estruturação de um ambiente físico e socialmente acessível, ou seja, que permita a sua inserção social. Por último, pressupomos que na vida em sociedade, a presença de pessoas com deficiência, autônomas, é essencial para a criação de uma cultura inclusiva.

Nesses termos, a inserção social depende de esforços tanto da sociedade quanto das pessoas com deficiência, em uma relação dinâmica. Enquanto o primeiro pressuposto alude à responsabilidade social, os demais também implicam a atuação - e responsabilidade - da

1 Alusão a letra da música intitulada Comida, de Arnaldo Antunes, Sérgio Brito e Marcelo Fromer. 
pessoa com deficiência. Com base nestes princípios, temos adotado como estratégia básica de ação a participação central de pessoas com deficiência, as quais assumem função de facilitadoras da inclusão (LIRA, 2007; 2012; 2013).

Entre as calçadas focalizadas nesse estudo, algumas são novas, fazendo parte de projeto ainda em execução. Isso faz com que a avaliação das condições de acessibilidade dessas calçadas assuma proeminência desde que, em sendo constatada a necessidade de intervenções, estas podem - e devem - ser realizadas antes da conclusão das obras.

Com efeito, a acessibilidade em edificações e vias públicas é um direito das pessoas com deficiência, o qual é garantido pela legislação federal, por meio de decretos como o $5.296 / 2004$ e outros mais recentes. Dessa forma, os projetos de arquitetura e de engenharia, quando destinados à construção desses espaços, devem incorporar as disposições de ordem técnica consubstanciadas nesses decretos, em conformidade ainda com Normas da Associação Brasileira de Normas Técnicas (ABNT) tais como a NBR 9050:2004 (Montenegro, Santiago e Sousa, 2009).

A acessibilidade em Instituições de Ensino Superior (IES) também é um direito garantido através do Decreto 5.296/2004 e para cumprir as determinações do mesmo, as universidades brasileiras vem se organizando e ampliando gradualmente o número de ações voltadas à inclusão de pessoas com deficiência. Com o estímulo do Programa Incluir, do Ministério de Educação (MEC), núcleos de acessibilidade vem sendo criados em muitas universidades, os quais se colocam como órgãos responsáveis por gerenciar as ações nessa área (Lira, 2014a). Esse é o caso da UFPE, cujo Núcleo de Acessibilidade foi criado em junho de 2014, assumindo, entre outros, o desafio de estimular a criação de uma cultura inclusiva nessa universidade, de forma a favorecer a promoção da acessibilidade pedagógica, linguística, atitudinal, tecnológica e física, entre outras.

No tocante a acessibilidade física, ações tem sido realizadas em algumas Instituições Federais de Ensino Superior (IFES) na busca pela criação de condições de acesso e livre circulação que possam garantir o direito de ir e vir das pessoas com deficiência. Esse é o caso, por exemplo, da Universidade Federal do Ceará (UFC), na qual ações dessa natureza tem sido realizadas através de atividades de ensino, pesquisa e extensão e de trabalhos em parceria entre a Secretaria de Acessibilidade UFC Inclui e a Coordenadoria de Obras e Projetos (COP). Entre outros procedimentos, essas ações envolvem: (a) vistorias técnicas e análise de projetos, a partir das quais se apresenta diagnóstico e recomendações que possam servir de base à revisão desses projetos e adequação das edificações e vias; e (b) execução de projetos de adequação de estruturas físicas, priorizando-se as unidades acadêmicas ou campi em que há alunos com deficiência matriculados (Santiago, 2011; Lira, 2014b). Alguns desses trabalhos são retomados por Santiago (2011) e Cunha (2014), a exemplo do Projeto Acesso UFC, desenvolvido entre 2002 e 2003, pela antiga Superintendência de Obras e Planejamento (PLANOP) em parceria com o Departamento de Arquitetura e Urbanismo, e que pode ser tomado como modelo por outras Universidades. Através de perspectivas distintas, as autoras apresentam as ações e condições de acessibilidade física na UFC, observando o processo de construção de uma cultura de inclusão em associação à incorporação de parâmetros de acessibilidade na realização de obras e reformas, bem como de novos projetos. Na análise, Santiago (2011) constata que "o atendimento às normas de acessibilidade passou a ser adotado quando da elaboração de projetos para as novas edificações" (id. ibid., p. 8), embora ainda haja muito a ser feito para que a UFC alcance um nível satisfatório de acessibilidade em sua estrutura física.

$\mathrm{Na}$ atualidade, a identificação de parâmetros de acessibilidade está vinculada ao conceito de 
desenho universal, voltado a ambientes e equipamentos que atendam a um público diverso e não somente a pessoas com deficiência. A ideia de desenho universal fundamenta, por exemplo, a Norma Brasileira 9.050: 2004, utilizada como referência para este trabalho e que visa permitir o uso do ambiente, de maneira autônoma e segura, pela maior quantidade possível de pessoas, independente de idade, estatura ou limitação de mobilidade ou percepção.

No tocante a calçadas, os parâmetros de acessibilidade são definidos para permitir que os pedestres caminhem com fluidez, conforto e segurança e estão associados a largura e espaço livre, piso, rebaixos de meio-fio e sinalização tátil, entre outros aspectos (ver Cavalcante, Lira, Santiago e Maciel, 2013). A presença de bancas de comércio no meio da calçada, por exemplo, se constitui em obstáculo que não somente limita a circulação de pedestres, mas muitas vezes impede o ir e vir, especialmente no caso de pessoas com deficiência motora e/ou visual. Já a ausência de rebaixamento de guias e/ou sinalização tátil são barreiras que ferem esse direito para usuários de cadeiras de rodas e pessoas cegas, respectivamente. Conforme bem colocado por Pessoa (2010): “... o direito de IR e VIR, princípio básico da cidadania, tem sido constantemente negado a uma parcela representativa da população do nosso país: o segmento das pessoas portadoras de deficiência física". A autora, que é professora da rede municipal de ensino de Fortaleza, tetraplégica e tem uma atuação de destaque no movimento social das pessoas com deficiência, questiona: "como IR e VIR e sair em busca de educação escolar, (...) profissionalização e lazer se as calçadas da nossa cidade encontram-se, em sua maioria, em péssimo estado e não contam com rebaixamento de guias e sinalização que permitam que essas pessoas transitem em segurança pela cidade?" E conclui, pontuando: "É necessário, portanto, que sejamos lembrados pelos arquitetos e engenheiros em seus projetos; (...) pelas autoridades municipais, quando da análise de projetos e execução de obras públicas..." (id.ibid., p. 53).

Ainda que possam parecer banais, as considerações de Pessoa são pertinentes não só porque nos reportam a obstáculos que dificultam o dia-a-dia de pessoas com deficiência, mas também porque apontam para aspectos que podem contribuir para a redução ou eliminação das mesmas. O ato mental de lembrar das pessoas com deficiência - que via de regra está associado a formação, convivência com essas pessoas e familiaridade com as condições que apresentam - pode fazer grande diferença no exercício da profissão por engenheiros, arquitetos, entre outros. Como exercícios de empatia para com pessoas com deficiência motora e cegas, atividades de sensibilização tem sido realizadas em que se usa cadeiras de rodas e/ou muletas e se anda com olhos vendados, buscando-se vivenciar e sentir o ambiente externo como o fazem pessoas que apresentam essas condições de deficiência (Lira, 2014b). Fica a sugestão para aqueles que atuam na UFPE.

No presente trabalho, as calçadas avaliadas constituem caminhos frequentemente pecorridos pela comunidade acadêmica da UFPE e visitantes. Por elas, servidores e estudantes com deficiência da UFPE caminham nos seus deslocamentos diários quando na chegada e saída da Universidade e/ou no trajeto entre um prédio e outro, seja para almoçar e/ou jantar no RU, para assistir aulas, encontrar colegas, fazer pesquisas em bibliotecas ou outras finalidades. Dessa forma, tais calçadas representam lugares que conectam, como expressa a mensagem dos paineis publicitários da UFPE, distribuidos pelo seu campus (ver figura 5). Nesses paineis, um sub-texto diz: em 2015, conecte-se, estimulando as pessoas a utilizarem as novas vias. No entanto, para os usuários com deficiência isso só será possível se nelas forem incorporadas os parâmetros de acessibilidade recomendados pelas normas técnicas da NBR 9.050: 2004, cumprindo-se a legislação vigente. 


\section{OBJETIVO}

O presente estudo tem por objetivo a descrição e análise das condições de acessibilidade observadas em espaços da Universidade Federal de Pernambuco (UFPE), conforme verificação in loco e com vistas a uma avaliação diagnóstica.

\section{METODOLOGIA}

A pesquisa é de caráter qualitativo e exploratório, tomando-se como objeto de estudo as condições de acessibilidade de calçadas da UFPE. A pesquisa de campo foi realizada no mês de dezembro de 2014, por iniciativa do Grupo de Trabalho (GT) Acessibilidade Física, da Comissão Permanente de Acessibilidade do Centro de Educação da Universidade Federal de Pernambuco. Contou com a participação dos membros desse GT, o qual é composto por três docentes e três alunos com deficiência. Entre os alunos, dois são da pedagogia e apresentam condições de deficiência motora (paraplegia e fibromialgia) e 0 terceiro, da música, é cego. Aqui são chamados Marcos, Bianca e Rafael, respectivamente.

\section{Área - Espaços Verificados}

Quanto a delimitação, o estudo abrange trechos da área interna do Campus Recife, no entorno dos seguintes prédios: Centro de Educação (CE), Núcleo Integrado de Atividades de Ensino (Niate CFCH/CCSA), Restaurante Universitário (RU), Centro de Artes e Comunicação (CAC) e Centro de Filosofia e Ciências Humanas (CFCH) (ver figuras 1-2).

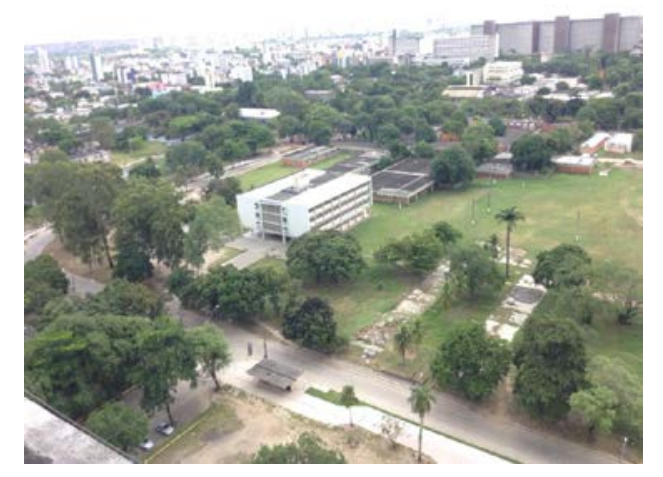

Figura 1 - Vista aérea de vias no entorno do Niate e CE

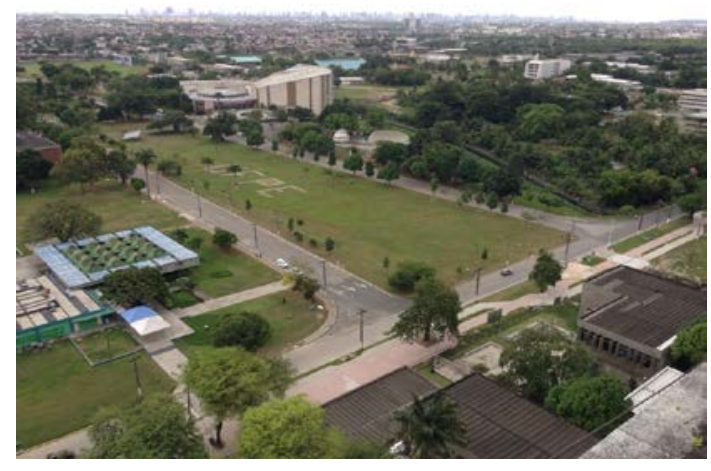

Figura 2 - Vista aérea de vias no entorno do RU e CAC

Observe-se que o campus tem uma dimensão bastante ampla e que os prédios estão distribuídos pelo mesmo de forma tal que há uma distância considerável entre um prédio e outro. Para ir do CE até o RU, por exemplo, o pedestre precisa se deslocar por um percurso de aproximadamente 200 metros.

\section{Métodos, Técnicas e Procedimentos}

A pesquisa de campo constou da observação das vias e passeios, através da análise walkthrough em grupo que incluiu três pessoas com deficiência e levantamento técnico envolvendo um check list das condições de acessibilidade. Em ambas as ocasiões, foi feito o registro de dados, tanto escrito quanto fotográfico. Na caminhada inicial, realizada na manhã do dia 5 de dezembro, os seis membros do GT Acessibilidade Física examinaram as condições da estrutura física desses espaços em função das possibilidades oferecidas para 
a locomoção e uso, com segurança e autonomia, por um aluno paraplégico e um aluno cego, buscando verificar se as mesmas se encontravam em conformidade com as regras e recomendações da Associação Brasileira de Normas Técnicas (ABNT) no que se refere a condições de acessibilidade. Já o levantamento técnico foi realizado em 30 de dezembro, com a utilização de instrumentos básicos de aferição métrica para medição das calçadas e apoio de formulário básico para a avaliação de condições de acessibilidade, conforme apresentado no Guia de Acessibilidade: espaço público e edificações, elaborado por Montenegro, Santiago e Sousa (2009). No tocante as calçadas, esse formulário considera aspectos tais como largura, piso, obstáculos, rebaixamento de guias, sinalização tátil e equipamentos urbanos.

Com início e final no CE, a caminhada e o levantamento técnico incluiram o deslocamento por entre os prédios acima mencionados, em um percurso total de aproximadamente 500 metros. Observações foram também realizadas no tocante as calçadas dos halls de entrada de cada prédio, utilizando se, no total, um tempo médio de aproximadamente duas horas e trinta minutos em cada ocasião no campo. Vale ressaltar que os trechos percorridos incluiram tanto calçadas novas, ainda em fase de construção, quanto calçadas antigas.

O estudo foi realizado com fluidez e sem maiores transtornos. Desde que as novas calçadas ainda estão em construção, foi possível observar pedreiros e outros profissionais em atividade de colocação de piso tátil, polimento e tintura das calçadas, entre outras.

\section{RESULTADOS}

Nessa seção, descrevemos e analisamos as condições de acessibilidade dos espaços em foco, conforme verificação in loco.

\section{Condições de Acessibilidade das Novas Calçadas}

No geral, as novas calçadas são bastante largas, seguindo o que recomenda a ABNT quanto a dimensão de faixa livre e permitindo o trânsito por pessoas com deficiência motora e visual. Entretanto, há trechos em que árvores, postes e mesmo painel com publicidade obstruem o caminho do pedestre, pois não estão na faixa a qual deveria ser destinada ao serviço (ver figura 5).

O piso das novas calçadas é geralmente feito de placas de concreto, propiciando superfície regular, adequada as suas finalidades. No entanto, há trechos em que há inclinação acentuada, certamente maior do que os 3\% permitidos, o que resulta em dificuldade e insegurança principalmente para pessoas cegas.

Não há rebaixamentos das novas calçadas, exceto nos trechos em que se encontram as duas paradas de ônibus (esquina CE e próximo a nova entrada CAC) e as vagas reservadas a pessoas com deficiência na entrada do $\mathrm{CFCH}$. Na ausência dos rebaixos, o usuário de cadeiras de rodas fica impedido de acessar essas calçadas, sendo forçado a transitar pela pista (ver figuras 3 e 6). Desde que as calçadas são longas, perdura-se o risco de acidentes e constrangimento. Isso foi vivenciado pelos membros do GT Acessibilidade Física, os quais foram obrigados a trafegar pela pista durante quase todo o trajeto percorrido.

É recomendado, por exemplo, que haja rebaixamento de calçadas e guias em esquinas e trechos em que há faixas de pedestres, para possibilitar a travessia de todos os usuários com conforto e segurança. Esta norma, no entanto, não é atendida no caso das novas calçadas da UFPE, conforme demonstram as figuras 4 e 5 . Dessa forma, fica o cadeirante impedido de transitar mesmo na faixa de pedestres em frente a entrada do RU, na qual há fluxo intenso, especialmente em horários de refeições.

A ausência de rebaixamentos também implica na inexistência de rota acessível para 
pessoas em cadeiras de rodas, interligando os pavimentos de uso coletivo ou público. Sem a rota acessível, o usuário de cadeiras de rodas não tem como ir e vir de um prédio a outro, a não ser transitando pela pista, sem nenhuma segurança.

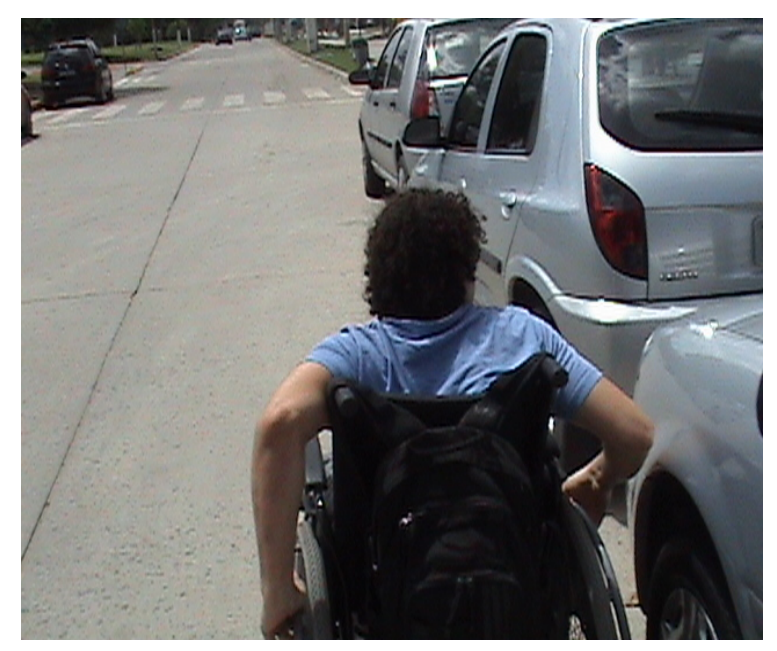

Figura 3 - Marcos se locomovendo em direção ao RU - CAC. Vai pela pista porque não há rebaixos de guias - acesso calçada

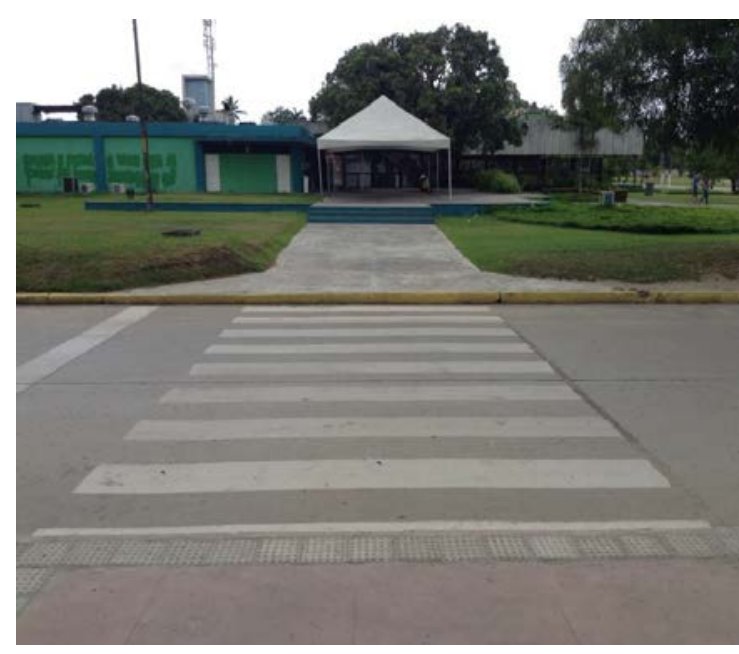

Figura 4 - Trecho frente ao RU - CAC, com faixa de pedestre sem rebaixo e piso de alerta instalado junto ao meio fio

Com exceção da calçada interna do $\mathrm{CFCH}$, há sinalização tátil sendo instalada nas novas calçadas, a qual inclui piso tátil de alerta e piso tátil direcional. No entanto, em vários trechos das composições criadas com esses pisos há problemas que limitam a orientação fornecida a pessoa cega, impedindo-a de identificar caminhos a serem seguidos. Nas calçadas em frente a nova entrada do CAC e na lateral do CE/em frente ao Niate (lado oposto), por exemplo, há interrupções e descontinuidade da rota central por longos trechos em que há canteiros de gramado, o que impede a pessoa cega de prosseguir o fluxo (ver figura 8). Há também ausência de sub-rotas ligando a rota central a áreas de acesso a edificações e a parada de ônibus próxima, o que impossibilita a orientação quanto a necessárias direções e sub-rotas a serem seguidas (ver figura 7). Para a entrada no CAC, além da falta de ligação entre as sinalizações dentro e fora do prédio, há também obstáculos representados por caixas de inspeção e desnível.

Quanto a sinalação tátil nas calçadas da UFPE, há ainda outros aspectos que comprometem a orientação fornecida a pessoa cega, precisando ser corrigidos. Chama a atenção, por exemplo, a instalação de piso tátil de alerta no perímetro de canteiros com árvores, ao invés de balizadores, conforme recomendam as normas técnicas. Isso confunde a pessoa cega que ao tentar seguir as rotas criadas nesses perímetros, permanece dando giros ao redor das árvores, sem continuar o seu trajeto. Na esquina do CE/Niate junto a parada de ônibus, onde há painel publicitário obstruindo o caminho, observa-se que a sinalização tátil direcional foi desviada da rota que seguia a fim de contornar o espaço em que se encontra o painel, o que mais confunde do que orienta a pessoa cega (ver figura 5). No trecho em frente ao RU-CAC, com faixa de pedestre sem rebaixo, verifica-se a instalação de piso tátil de alerta junto as guias, desconsiderando-se a recomendação para a instalação desse piso a distância de $50 \mathrm{~cm}$ da pista de rolamento (ver figura 4). É importante, pois, que os projetistas revejam as normas técnicas relativas à sinalização a fim de atendê-las quando 
da construção desse e de todos os demais rebaixamentos necessários nas calçadas da UFPE.

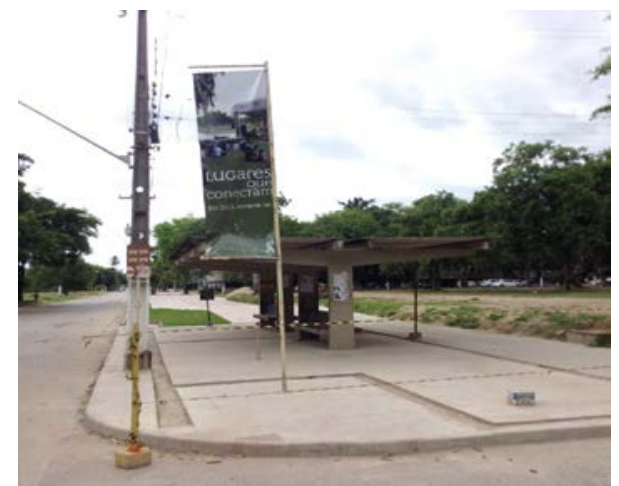

Figura 5 - Trecho na esquina do CE, sem rebaixo de guias e com painel obstruindo caminho. Observe-se que há desvio na sinalização contornando painel

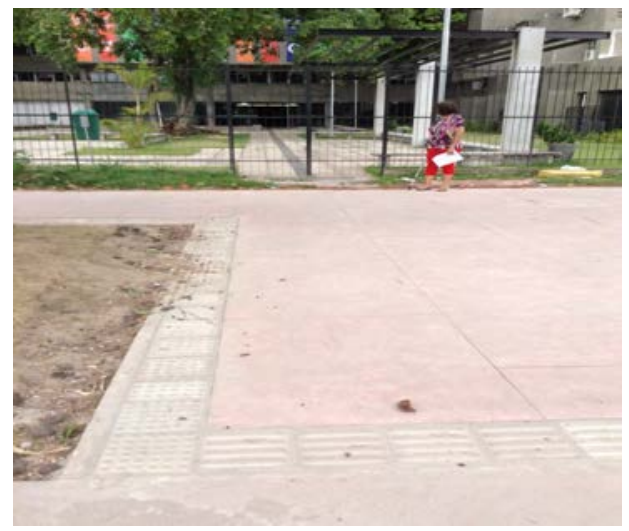

Figura 8 - Rafael para, sem saber por em frente a portão CAC. Ausência de ligação entre sinalizações dentro e fora

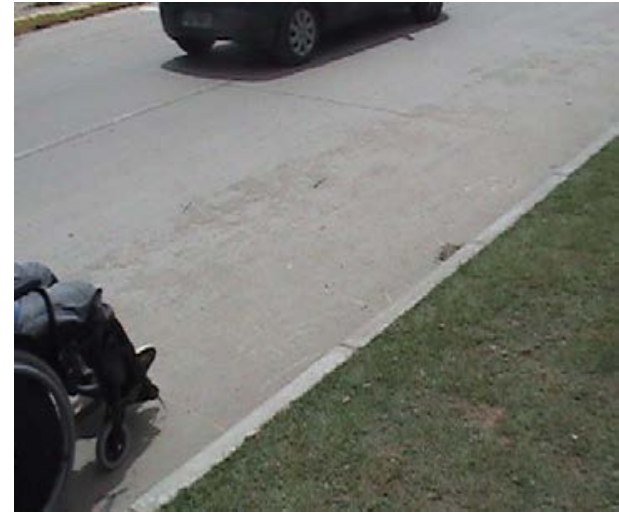

Figura 6 - Marcos e veículo, ambos em locomoção, dividem a pista. Marcos se expõe a constrangimento e risco porque não há rebaixos para usar a calçada

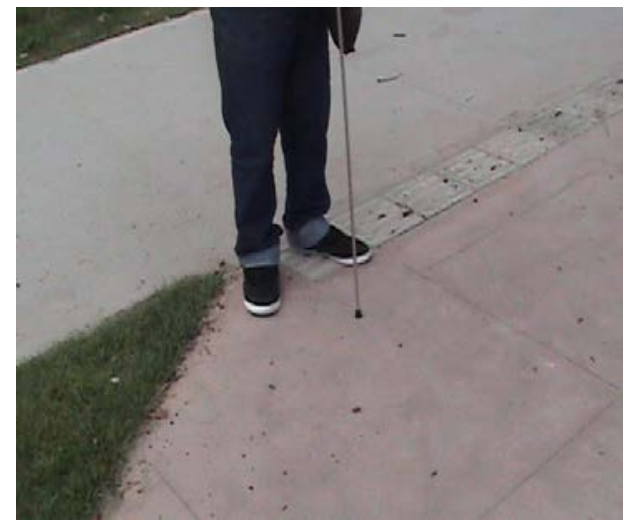

Figura 7 - Bianca observa obstáculos

onde prosseguir porque há interrupção de trajeto de sinalização tátil

Há muitos trechos nos quais não há piso de alerta próximo as guias da calçada, o que impede que a pessoa cega perceba o limite das mesmas (ver figura 5). Finalmente, os trajetos que vem sendo criados com piso tátil não fazem a necessária ligação entre as novas e às antigas calçadas, o que reduz os percursos de rota acessível, impedindo o livre acesso e circulação por entre os prédios do $\mathrm{CE}$, Niate, RU, CAC e CFCH por parte das pessoas cegas (ver figura 4).

\section{Condições de Acessibilidade das Calçadas Antigas}

No geral, a maioria das calçadas antigas no entorno do $\mathrm{CE}, \mathrm{CFCH}$ e $\mathrm{CAC}$ tem largura inferior a mínima admissível, de 1,20m. Além disso, há trechos em que se verifica obstáculos como caixas de inspeção e escada de acesso a estacionamento, os quais interrompem ou impedem a passagem por pessoas com deficiência motora e/ou visual. Desde que todas essas calçadas se encontram ao lado de áreas de estacionamento, elas são constantemente obstruídas pelos carros estacionados, que via de regra invadem o limite 
das mesmas (ver figuras 9 e10).

Quanto às áreas destinadas a pedestres e a veículos nos espaços no entorno desses prédios, verifica-se que as calçadas foram quase anuladas em função da gradual ampliação das áreas destinadas ao estacionamento de veículos, que passaram a abranger, inclusive, o quadrilátero referente a terreno situado no centro desses prédios, no qual os carros são estacionados desordenamente. Mesmo com tal ampliação, há ainda uma superlotação dos estacionamentos e um fluxo exacerbado de veículos no entorno dos prédios, em detrimento do fluxo de pedestres, para os quais os espaços se tornam cada vez mais limitados, mesmo para o ir e vir. Na reforma e reorganização desses espaços, será importante garantir não somente o trânsito e circulação, mas também à permanência dos membros da comunidade acadêmica, criando-se áreas de convivência com árvores, bancos e outros equipamentos que possam estimular a interação entre eles.

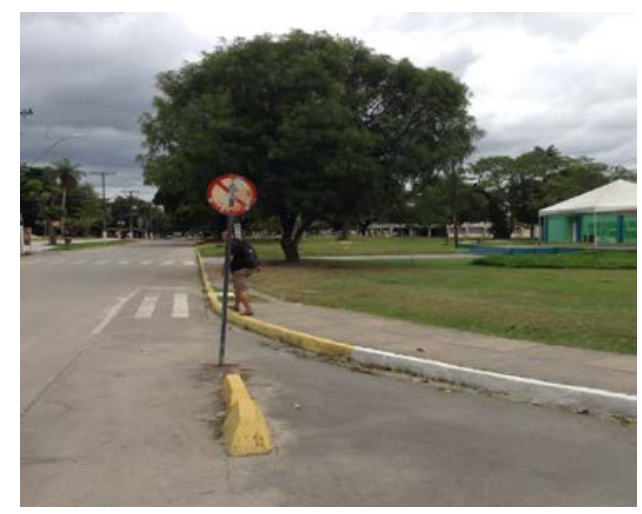

Figura 9 - Trecho próximo a entrada do RU via escadas, com largura inferior a mínima admissível, sem rebaixo e sem sinalização tátil

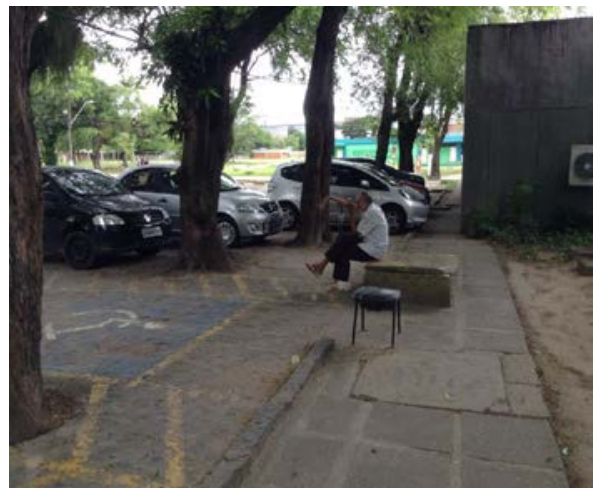

Figura 10 - Trecho entrada usual CAC em direção a RU. Largura inferior a mínima admissível, piso irregular, desníveis e obstáculos

O piso das calçadas antigas no entorno do $\mathrm{CE}, \mathrm{CFCH}$ e $\mathrm{CAC}$ é geralmente feito de concreto, apresentando-se, no entanto, em péssimo estado de conservação, com muitos buracos e desníveis. Há, inclusive, vários trechos em que há somente areia ou mesmo mato no lugar do piso das calçadas.

Não há rebaixamentos nessas calçadas, exceto nos trechos em que se encontram as vagas reservadas a pessoas com deficiência na entrada do CE e do CAC e no trecho em frente ao CE. Também não há sinalização tátil instalada nas calçadas, com exceção daquela no hall de entrada do CE.

Quanto as calçadas antigas no entorno do RU e do Niate, há uma diferença entre as condições de acessibilidade do trecho próximo a entrada do RU que dá acesso a rampa e aquelas dos demais trechos. No primeiro, a calçada tem uma dimensão apropriada e possui rebaixo de guia, assim como sinalização tátil, ainda que a rota instalada passe por obstáculos como um poste e um equipamento telefônico. Nos demais trechos, a largura é inferior aos 1,20m mínimos admissíveis, há obstáculos como placas de sinalização de trânsito e não há rebaixos e nem sinalização tátil (ver, por exemplo, figura 9).

Em uma visão panorâmica desses trechos (ver figuras 1 e 2) é possível verificar detalhes que apontam para a necessidade de intervenções quanto a acessibilidade. Da entrada do $\mathrm{RU}$ que dá aceso a rampa à entrada desse prédio pelas escadas há uma diminuação 
gradual da calçada, que leva ao término da mesma antes mesmo da faixa de pedestre, o que impossibilita o deslocamento de usuário de cadeira de rodas pela calçada e uso da faixa de forma confortável e segura. Em função do design arrojado do prédio do RU, no trecho entre a faixa de pedestre e a esquina em direção ao Niate a calçada é substituída por gramado em terreno inclinado, o que, portanto, impossibilita a circulação nesse espaço. No trecho da esquina do RU até o prédio do Niate a calçada, além de bem estreita, está em péssimas condições de conservação. Há mesmo muitos espaços em que não existe piso, mas somente areia, gramado ou mesmo mato, inclusive próximo a rampa de acesso aquele prédio. Dessa forma, não há condições apropriadas que permitam que pessoas com deficiência motora e/ou visual se locomovam por essas calçadas antigas entre o RU e 0 Niate, de forma autônoma e segura.

\section{Condições de Acessibilidade das Calçadas nos Halls de Entrada das Unidades}

A observação das calçadas nos halls de entrada dos prédios focalizados nesse estudo demonstra que há diferentes condições de acessibilidade nas mesmas, o que certamente está associado a diferentes níveis de disseminação do conhecimento sobre inclusão de pessoas com deficiência/acesssibilidade nos centros e demais unidades acadêmico e/ou administrativas da UFPE. Positivamente, condições como rebaixos de guias e sinalização tátil são verificadas na entrada do CE e em uma das entradas do RU; e rampas de acesso são verificadas na entrada do Niate e na entrada usual do CAC, o que indica a disseminação/aplicação desse conhecimento no âmbito desses prédios, mesmo ainda havendo a necessidade de adequações na estrutura física dos mesmos.

Desde que o CAC abrange o Departamento e curso de Arquitetura e Urbanismo e mestrado em Ergonomia, este desafio pode ser lançado no âmbito dos cursos ofertados, em níveis de graduação e/ou pós-graduação. Com efeito, se os colegiados do Departamento e dos cursos se interessarem e passarem a incluir a abordagem do tema sobre acessibilidade física e atitudinal nas disciplinas que ofertam, o conhecimento sobre pessoas com deficiência pode ser adquirido pelos futuros profissionais da área e aplicado no mercado de trabalho, cuja demanda é crescente, inclusive na própria UFPE. Essa tendência tem sido observada em algumas universidades, a exemplo da UFC, que em 2012 criou disciplina voltada ao estudo do desenho universal e acessibilidade.

Seguindo-se a mesma lógica de disseminação do conhecimento, que é uma das funções básicas da universidade, merece destaque ação do Departamento de Psicologia e Orientação Educacionais do Centro de Educação (DPOE/CE), que incluiu temática sobre a pessoa com deficiência/acessibilidade pedagógica e atitudinal em todas as disciplinas que oferta. Com isso, garante-se que os profissionais formados através dos cursos de pedagogia e/ou licenciaturas da UFPE possam ser preparados para responder as demandas do mercado educacional, atuando em prol da inclusão escolar e social. Esta e outras ações inclusivas realizadas no âmbito do CE certamente tem reflexo nas condições de acessibilidade física verificadas nesse Centro.

Já no caso do $\mathrm{CFCH}$, somente o rebaixo de guias próximo a vagas demarcadas para pessoas com deficiência é verificado na entrada central do prédio, o que indica pouca ou nenhuma disseminação do conhecimento sobre acessibilidade no âmbito desse Centro. Observe-se que as calçadas na entrada do $\mathrm{CFCH}$, que foram concluídas recentemente, abrangem uma longa área, devendo contar com o rebaixo de guias não somente na sua área central junto as vagas reservadas (conforme se verifica), mas também em outros trechos, incluíndo esquinas e demais locais de grande fluxo, em conformidade com as normas técnicas e legislação. No arranjo atual, as novas calçadas do $\mathrm{CFCH}$ se juntam, nas 
duas extremidades, a trechos de calçadas antigas, nas quais se verifica desníveis, obstáculos e rebaixamento de guias com largura inferior a mínima admissível, com notável discrepância entre as mesmas.

De uma forma geral, há uma grande discrepância entre as calçadas antigas e as calçadas novas da UFPE no tocante a aspectos tais como largura, obstáculos e qualidade de piso. Além disso, não se percebe nenhuma tentativa de ligação ou continuidade entre essas calçadas, sendo que em muitos trechos há notável desnível e obstáculos que impedem a passagem entre uma e outra calçada. É necessário, pois, rever os trechos de ligação entre essas calçadas, fazendo os acabamentos e arranjos apropriados de forma a permitir a conexão e trânsito entre elas.

\section{INTERVENÇÕES NECESSÁRIAS}

Os resultados desse estudo demonstram que há necessidade de realizar intervenções na estrutura física das calçadas da UFPE de forma a adequá-las quanto a condições de acessibilidade tais como rebaixamento de guias, sinalização tátil, entre outras. Isso se aplica tanto as calçadas antigas quanto as novas calçadas, as quais, ainda em fase de construção/acabamento, devem passar por adequações em alguns trechos, de forma a atender as normas técnicas brasileiras, cumprindo a legislação em vigor. Nessa seção, apresentamos as intervenções/adequações que devem ser realizadas nas calçadas, com base nos dados descritos e analisados nos tópicos anteriores.

\section{Adequações nas Novas Calçadas}

1. Devem ser eliminados os obstáculos possíveis nas faixas livres das calçadas;

2. Considerando que as calçadas são muito longas, distâncias devem ser estimadas para a construção de tantos rebaixamentos de guias quantos se fizerem necessário para o uso confortável e seguro das calçadas por usuários de cadeiras de rodas, observando-se o fluxo, acesso a pavimentos, entre outros aspectos.

3. Devem ser construídos rebaixamentos de calçadas e guias em esquinas e trechos em que há faixas de pedestres, para possibilitar a travessia de todos os usuários com conforto e segurança;

4. Deve ser construída uma rota acessível para pessoas em cadeiras de rodas, interligando os pavimentos de uso coletivo ou público. Sem a rota acessível, o usuário de cadeiras de rodas não tem como ir e vir de um prédio a outro, a não ser transitando pela pista, sem nenhuma segurança;

5. A sinalização tátil instalada nas novas calçadas deve ser revista e complementada em vários trechos (como nova entrada CAC, lateral CE/frente Niate), de forma a solucionar problemas que impedem a identificação de caminhos pela pessoa cega, a exemplo das interupções e descontinuidade da rota central e ausência de sub-rotas ligando a rota central a áreas de acesso a edificações, parada de ônibus e outros equipamentos urbanos;

6. Quanto a sinalização tátil, devem ser corrigidos ainda equívocos como:

- instalação de piso tátil de alerta no perímetro de canteiros com árvores, ao invés de balizadores, conforme recomendam as normas técnicas;

- desvio de rota de piso tátil a fim de contornar espaço em que há painel publicitário obstruindo o caminho na esquina do CE/Niate junto a parada de ônibus;

- instalação de piso tátil de alerta junto as guias, desconsiderando-se a recomendação para a instalação desse piso a distância de $50 \mathrm{~cm}$ da pista de rolamento (em trecho em frente ao $\mathrm{RU}-\mathrm{CAC}$, com faixa de pedestre sem rebaixo); 
- ausência de piso de alerta próximo as guias da calçada (em vários trechos), o que impede que a pessoa cega perceba o limite das mesmas;

- ausência das necessárias conexões entre as novas e as antigas calçadas, o que reduz os percursos de rota acessível para a pessoa cega.

\section{Adequações nas Calçadas Antigas}

Considerando as péssimas condições em que se encontra a maioria das calçadas antigas focalizadas nesse estudo, torna-se imperativo reformá-las ou reconstruí-las para permitir a circulação e o livre trânsito de todos os tipos de pedestres, com fluidez, conforto e segurança. Para a reconstrução, o projeto deve incorporar parâmetros de acessibilidade referentes a largura e espaço livre, piso, rebaixos e sinalização tátil, entre outros, em atendimento a NBR 9.050: 2004.

Desde que no entorno dos prédios do $\mathrm{CE}, \mathrm{CFCH}$ e CAC os espaços destinados a veículos tem limitado aqueles destinados aos pedestres, é necessário que o projeto inclua a reorganização desses espaços, de forma a garantir não somente o trânsito e circulação, mas também a permanência dos membros da comunidade acadêmica em áreas de convivência, estimulando a interação entre eles.

Quanto as calçadas antigas no entorno do RU e do Niate devem ser buscadas soluções para os problemas relatados, de forma a eliminar as barreiras, aliando-se a ergonomia ao design.

\section{Adequações nas Calçadas dos Halls de Entrada das Unidades}

A análise das condições de acessibilidade nas calçadas dos halls de entrada das unidades focalizadas nesse estudo demonstra que há necessidade de adequações na maioria dos halls, em diferentes níveis e condições. Dessa forma, é importante que as direções dos centros e demais administradores estejam atentos a essa necessidade e sejam convocados a adotarem as devidas providências para a realização das adequações, de forma a garantir o direito de ir e vir nessas calçadas. Nos Centros que lidam com áreas de conhecimento associadas a temas relativos a inclusão de pessoas com deficiência/acessibilidade (por exemplo, educação, psicologia e arquitetura), pode-se envidar esforços para a realização de ações envolvendo ensino, pesquisa e extensão, através das quais esse conhecimento seja disseminado no âmbito das unidades.

\section{CONSIDERAÇÕES FINAIS}

Através da avaliação das condições de acessibilidade de calçadas da Universidade Federal de Pernambuco (UFPE), esse estudo conclui que adequações devem ser realizadas na estrutura física dessas calçadas de forma a permitir que pessoas cegas e/ou usuários de cadeiras de rodas possam transitar pelas mesmas, exercendo o direito de ir e vir. No estudo, tais adequações são apresentadas e discutidas com vistas a adoção das providências cabíveis pela UFPE em conjunto com a autora do projeto e com a empresa de engenharia e construções responsável pela execução das novas calçadas, ainda não concluídas.

No tocante as antigas calçadas, torna-se imperativo reformá-las ou reconstruí-las, de maneira que elas possam, junto com as novas calçadas, compor um todo harmônico e efetivamente acessível, agregando ainda mais valor a rica paisagem da UFPE.

Como outras instituições de ensino superior brasileiras, a UFPE vem se organizando para criar condições de acessibilidade nos seus campi, de forma a cumprir as determinações legais dispostas no Decreto 5.296/2004, entre outros. Assim, certamente se empenhará para adequar a estrutura física de suas calçadas, contando, inclusive, com o apoio do recém 
criado Núcleo de Acessibilidade, assim como da Comissão Permanente de Acessibilidade do Centro de Educação e outras instâncias.

A análise das condições de acessibilidade das calçadas no entorno de prédios da UFPE estimula a reflexão sobre as formas de organização desse espaço físico e sobre as possibilidades de interação, convivio e trocas a serem estabelecidas entre os membros da comunidade acadêmica nesse ambiente.

\section{REFERÊNCIAS NORMATIVAS E LEIS}

ASSOCIAÇÃO BRASILEIRA DE NORMAS TÉCNICAS. NBR 9050 - Acessibilidade de pessoas portadoras de deficiências a edificações, espaço, mobiliário e equipamento urbano. Rio de Janeiro: ABNT, 2004.

$\underline{0}$

BRASIL. Decreto $\mathrm{n}^{-}$5.296, de 2 de dezembro de 2004, que regulamenta as Leis $\mathrm{n} \underline{0} 10.048$, de 8 de novembro de 2000, que dá prioridade de atendimento às pessoas que especifica, e 10.098, de 19 de dezembro de 2000, que estabelece normas gerais e critérios básicos para a promoção da acessibilidade das pessoas com deficiência ou com mobilidade reduzida, e dá outras providências.

MONTENEGRO, Nadja G. S. Dutra; SANTIAGO, Zilsa Maria Pinto; SOUSA, Valdemice Costa de. Guia de Acessibilidade: espaço público e edificações. Fortaleza: Secretaria da Infraestrutura do Estado do Ceará - SEINFRA, 2009.

\section{REFERÊNCIAS BIBLIOGRÁFICAS}

CAVALCANTE, Maria Eduarda Sousa; LIRA, Ana Karina Morais de; SANTIAGO, Zilsa Maria Pinto; MACIEL, Antônia Kátia Soares. Acessibilidade espacial no entorno do Campus do Benfica da Universidade Federal do Ceará. Anais do XXII Encontros Universitários da Universidade Federal do Ceará (UFC), Fortaleza/CE, 2013.

CUNHA, Regina Lopes de Sousa da (2014) Uma visão perspectiva da acessibilidade física na Universidade Federal do Ceará. Em Ana Karina Morais de Lira; Ana Maria Monte Coelho Frota (Org.). Inclusão de alunos com deficiência na Universidade Federal do Ceará: o Projeto UFC Inclui em debate. Fortaleza: Edições UFC, 2014a, p. 201-210.

FONSECA, Juliane Figueiredo; RHEINGANTZ, Paulo Afonso. O ambiente está adequado? Prosseguindo a discussão. Em Produção, v. 19, n. 3, set/dez 2009, p. 502-513.

LIRA, Ana Karina Morais de Lira (2007) Projeto Acessibilidade Itinerante. Texto digitalizado, 10 páginas.

LIRA, Ana Karina Morais de (Coord.) (2012) Programa Educação Inclusiva e Acessibilidade. Proposta submetida e aprovada pelo Edital PROEXT 2013. Ministério da Educação, Secretaria de Educação Superior, Programa de Extensão Universitária (MEC/SESu).

LIRA, Ana Karina Morais de Lira (2007) A gente não quer só comida, a gente quer a vida, como a vida quer: relato de experiência de ecoturismo acessível em Sabiaguaba. Texto digitalizado, 8 páginas.

LIRA, Ana Karina Morais de. Apresentação. Em Ana Karina Morais de Lira; Ana Maria Monte Coelho Frota (Org.). Inclusão de alunos com deficiência na Universidade Federal do Ceará: o Projeto UFC Inclui em debate. Fortaleza: Edições UFC, 2014a, p. 11-21.

LIRA, Ana Karina Morais de. O Projeto UFC Inclui: propostas, ações e resultados. Em Ana Karina Morais de Lira; Ana Maria Monte Coelho Frota (Org.). Inclusão de alunos com deficiência na Universidade Federal do Ceará: o Projeto UFC Inclui em debate. Fortaleza: Edições UFC, 2014b, p. 25-77.

OLIVEIRA, Gilberto; RANGEL, Márcia; MONT'ALVÃO, Cláudia. Uma visão crítica sobre as metodologias utilizadas nas pesquisas de ergonomia do ambiente construído - A constelação 
de atributos. Em Ergodesin \& HCl, v. 1, n. 2, 2013, p. 10-17.

PESSOA, Nadja Soares de Pinho. Mosaico: um hino de amor à vida, Fortaleza: Secretaria Municipal de Educação, 2010, p. 53 (Artigo intitulado Cidadania, direito de todos?).

VASCONCELOS, Christianne Falcão e; VILLAROUCO, Vilma; SOARES, Marcelo Marcio. Contribuição da psicologia ambiental na análise ergonômica do ambiente construído. Em Ação Ergonômica, v. 5 , n. 3, 2010, p. 14-20. Disponível em www.abergo.org.br/revista/index.php/ae/article/download/92/89. Acesso em 30 Dez 2014.

VILLAROUCO, Vilma e ANDRETO, Luiz F. M. Avaliando desempenho de espaços de trabalho sob o enfoque da ergonomia do ambiente construído. Em Produção, v. 18, n. 3, set/dez 2008, p. 523-539. Disponível em http://www.scielo.br/scielo.php?pid=S0103-65132008000300009\&script=sci arttext Acesso em 30 Dez 2014.

SANTIAGO, Zilsa Maria Pinto. A acessibilidade de pessoas com deficiência nas instittuições de ensino superior: o caso da Universidade Federal do Ceará. Anais... V Jornada Internacional de Políticas Públicas, São Luis do Maranhão, 2011. 